\title{
Can Trabeculations Occur In Non-Schistosomiasis Obstructive Hydroureter?
}

\author{
Manas Babu, Devesh Bansal, Sony Mehta, Biju Pillai and H Krishnamoorthy* \\ Department of Urology, Lourdes Hospital, India
}

Submission: March 08, 2017; Published: May 24, 2017

*Corresponding author: H Krisnamoorthy, Consultant Urologist, Department of Urology, Lourdes Hospital, India, Tel: 0484-4123456/9847056690; Email: dr.moorthy65@gmail.com

\section{Abstract}

Trabeculations of the urinary bladder is well known to the Urologist. However trabeculations in an obstructed ureter associated with stone disease is rare. We describe this rare finding during ureteroscopy in a 48 years old male with obstructed ureteric stone.

Keywords: Stone disease, Trabeculations, Ureter, Ureteroscopy

\section{Introduction}

Trabeculations in urinary bladder is a common finding in patients with bladder outlet obstruction. However, trabeculations in the ureter is very rare and literature search did not reveal any such finding associated with stone disease. We present a case report of ureteral trabeculations identified in a patient with stone in the lower ureter.

\section{Case Report}

A 48 years old male with no co-morbidities presented with recurrent episodes of right flank colicky pain of one month duration. Ultrasound scan of abdomen and X ray KUB showed a right vesico-ureteric junction calculus of one $\mathrm{cm}$ size with moderate hydroureteronephrosis. He underwent right sided ureteroscopy and stone removal. During ureteroscopy the unusual finding of a grossly trabeculated lower ureter was seen up to the crossing of iliac vessels (Figure 1-3).

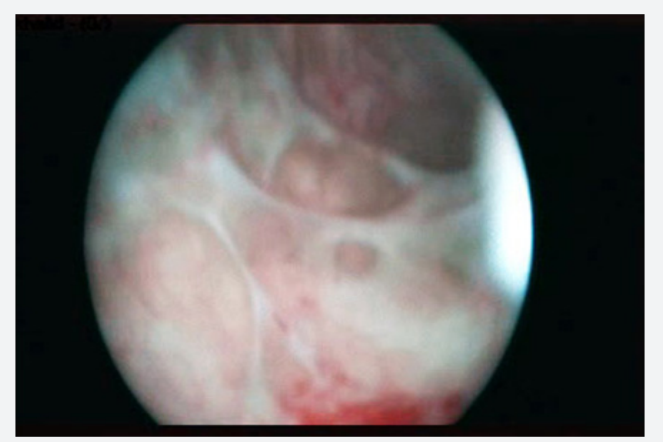

Figure 1: Ureteroscopic view of lower ureter showing ureteric trabeculations.
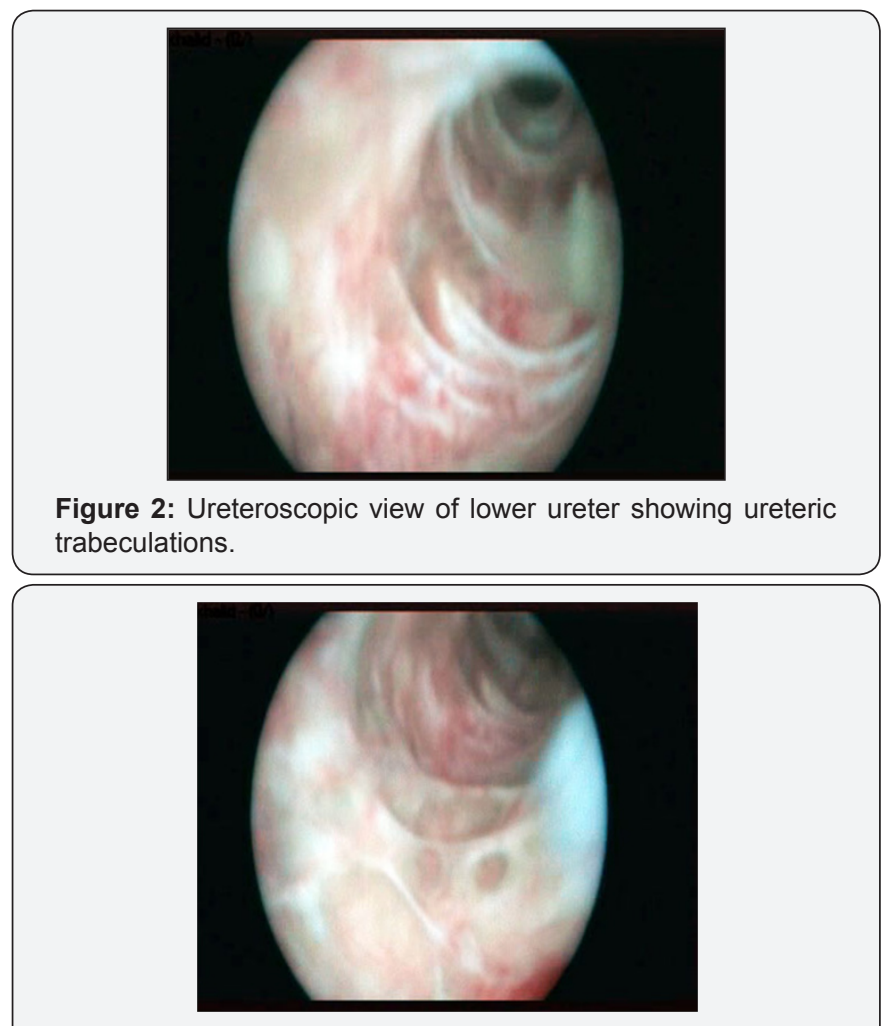

Figure3: Ureteroscopic view showing ureteric trabeculations in mid ureter.

\section{Discussion}

Trabeculations of the bladder is a well-known entity and is associated with bladder outlet obstruction. Trabeculations form due to hypertrophy of the muscular layer forming prominent 
separations [1]. The finding of a trabeculated ureter is rare and literature search did not reveal any such finding associated with stone disease. Miller et al. [2] reported tonic hydroureter in schistosomiasis, where the ureter becomes dilated, tortuous, thick-walled and trabeculated with marked ureteral muscle hypertrophy and active peristalsis. On detailed evaluation our patient, he did not reveal any history of travel to the middle-east or Mediterranean regions which are endemic for schistosomiasis. Trabeculations of the ureter may be confused is pseudodiverticulosis of the ureter of which 80 cases have been reported in the literature so far [3]. However pseudo-diverticulosis usually involves upper and middle ureter in contrast to trabeculations, which usually involve lower ureter. Our patient had obstructing lower ureter, probably of long duration, which had resulted in trabeculations of the lower ureter.

\section{Conclusion}

Trabeculations in ureter is very rare entity which can be occur in obstructive calculus disease of the ureter in addition to schistosomiasis.

\section{Reference}

1. Fam AM (1964) The problem of Bilharzial ureter. BJU Int 36: 211-219.

2. Miller MJ, Love E (1989) Parasitic Diseases: Treatment and Control. CRC Press, USA p. 9.

3. Wasserman NF, Posalsky IP, Dykoski R (1988) The pathology of ureteral pseudodiverticulosis. Invest Radiol 23(8): 592-598. 